\title{
Tango-Therapy: An Alternative Approach in Early Rehabilitation of Multiple Sclerosis
}

\author{
Luca Collebrusco, Giuseppina Di Tocco, Alessandra Bellanti \\ Rehabilitation Unit, Health Service of Umbria, Perugia, Italy \\ Email: luca.collebrusco@unipg.it
}

How to cite this paper: Collebrusco, L., Di Tocco, G. and Bellanti, A. (2018) TangoTherapy: An Alternative Approach in Early Rehabilitation of Multiple Sclerosis. Open Journal of Therapy and Rehabilitation, 6, 85-93.

https://doi.org/10.4236/ojtr.2018.63008

Received: July 12, 2018

Accepted: August 14, 2018

Published: August 17, 2018

Copyright $\odot 2018$ by authors and Scientific Research Publishing Inc. This work is licensed under the Creative Commons Attribution International License (CC BY 4.0).

http://creativecommons.org/licenses/by/4.0/

\section{c) (i) Open Access}

\begin{abstract}
Multiple sclerosis (MS) is a chronic inflammatory disorder of central nervous system (CNS), characterized by the presence of multifocal demyelination plaques with characteristic symptoms as fatigue, balance disorder, reduced endurance in gait and decrease in quality of life. The study supposed that the motor treatment through dance could represent useful therapeutic option, together with other treatments already in use such as the pharmacological and physiotherapy one. We included 9 person (6 male and 3 female) affected by relapsing-remitting multiple sclerosis (RRMS) with an expanded disability status scale (EDSS) score less than 3, underwent rehabilitation treatment with Argentine Tango (Riabilitango ${ }^{\circledR}$ method). The study lasted twenty months, considering a sixty-minute session a week. The aim of the study was to verify the real improvement of quality of life, fatigue, balance disorder and gait endurance due to the dance treatment. We collected outcomes data of Short Form 36 (SF-36) in physical function (PF) (45.56 \pm 21.42 vs. $69.44 \pm 23.64)$, vitality (VT) (45.00 \pm 7.90 vs. $67.77 \pm 6.18)$, social function (SF) (54.00 \pm 13.86 vs. $75.11 \pm 6.25)$, general health $(\mathrm{GH})(32.22 \pm 5.06$ vs. $54.11 \pm 5.20)$; Modified fatigue impact test scales (MFSI) (3.56 \pm 3.72 vs. $37.22 \pm 3.88$ ); Berg balance scale (BBS-it) $(33.89 \pm 4.12$ vs. $45.11 \pm 3.51)$; Six Minute Walk Test (6mWT), in distance $(\mathrm{m})$ (352.89 \pm 174.56 vs. $397.22 \pm 174.83)$, oxygen saturation in arterial blood (\%SpO2) $(87.67 \pm 3.35$ vs. $91.78 \pm 5.92)$ and beast per minute $(\mathrm{bpm})(82.67 \pm 13.08$ vs. $72.67 \pm 10.52)$. We found statistically significant $(\mathrm{p}<0.05)$ improvements in each evaluation scale. In conclusion, despite the small sample size included, the results confirm that Riabilitango ${ }^{\circledR}$ significantly leads to better functional performances in person affected by RRMS with EDSS less then 3, finding benefits in terms of quality of life. Data suggest that integration between dance treatment method and the pharmacological, could represent the useful approach.
\end{abstract}

\section{Keywords}

Multiple Sclerosis, Riabilitango Treatment, Balance Impairment, Fatigue, Walk 


\section{Introduction}

Multiple sclerosis (MS) is a chronic inflammatory disorder of central nervous system (CNS), characterized by the presence of multifocal demyelination plaques that affects in the world around 1,000,000 people aged between 17 and 65 years, with a major prevalence in female [1] [2]. In Italy in last 10 years, the annual average incidence has increased to 4.2 cases per 100,000 inhabitants, Sardegna in particular stands at 6.8 cases per 100,000 inhabitants [3]. There are different types of MS, we have considered into consideration the relapsing remitting one (RRMS) with an Expanded Disability Status Scale (EDSS) score less then 3 [4], due to their peculiar symptoms as far as the abnormal gait pattern characterized by the co-contraction of agonist-antagonist muscles and by the complex pattern of spasticity and ataxia, resulting in reduced physical exercise and increased fatigue that leading to a worst disability [5] [6]. Since the early stages of disease, fatigue has particular importance; leads to a loss of skills and a decrease in quality of life with an estimated prevalence between $70 \%$ and $90 \%$ of cases [7]. The study consists of motor therapy trough "Riabilitango ${ }^{\circledR}$ " method to person affected by RRMS with EDSS score less than 3. Riabilitango ${ }^{\circledR}$ is based on the usage of dance moves, figure, technique exercises and Argentine Tango music, chosen and combined according to the specific functional limitation, the real skill and the potentiality of the person, to improve balance, posture, quality and control of movement and mood. There are several studies in literature concerning Argentine tango approach efficacy in Parkinson disease (PD) in improving balance and functional mobility. These studies were limited by a reduced sample size and did not verified long term effects of the approach [8] [9]. Considering Argentin tango positive effects in improving balance and functional mobility, we decided to apply this approach on MS.

\section{Patients and Methods}

The study was conducted from November 2015 to June 2017 in Italian Multiple Sclerosis Association (AISM) headquarter based in Foligno (Italy). We included 9 people (Table 1), affected by RRMS and underwent dance sessions according with Riabilitango ${ }^{\circledR}$ method. Inclusion criteria were diagnosis of RRMS with EDSS score less than 3; exclusion criteria were relapses of the disease, pregnancy, acute orthopedic problems leading worst balance and gait, psychiatric disease.

All enrolled persons have accepted and signed informed consent. The limitation of the sample is due to the small number of people belonging to the AISM of Foligno (Italy) and to the inclusion criteria of EDSS less than 3; due to the same reasons was not possible to randomize data and to enrol a control group not affected by MS.

\section{Study Design}

Person affected by RRMS with an EDSS score less than 3 included in this pilot uncontrolled study, continued to take pharmacological therapy. Riabilitango ${ }^{\circledR}$ 
Table 1. Characteristics of the sample.

\begin{tabular}{cccc}
\hline & MALE & FEMALE & TOTAL \\
\hline Mean $\pm \mathrm{DS}$ & Mean $\pm \mathrm{DS}$ & Mean $\pm \mathrm{DS}$ \\
Age, $\mathrm{y}$ & $41.33 \pm 8.50$ & $48.67 \pm 8.65$ & $46.22 \pm 8.98$ \\
Weight, $\mathrm{Kg}$ & $74.00 \pm 4.0$ & $63.50 \pm 3.93$ & $67.00 \pm 6.42$ \\
Height, $\mathrm{h}$ & $1.75 \pm 0.70$ & $1.68 \pm 0.48$ & $1.70 \pm 0.62$ \\
BMI, $\mathrm{Kg} / \mathrm{h}^{2}$ & $30.21 \pm 10.48$ & $22.56 \pm 2.57$ & $25.13 \pm 6.79$ \\
\hline
\end{tabular}

Abbreviation: y, years. Kg, kilograms. h, height. Kg, kilograms. BMI, Body Mass Index.

session took place once a week for sixty minutes. We evaluate the follow outcome at the beginning (baseline) and at the and (twenty months) of treatment: short form health survey questionnaire (SF-36), modified fatigue impact scale (MFIS), Berg balance scale Italian version (BBS-it), the six-minute walk test (6mWT).

\section{1) Health-related quality of life (QoL)}

Standardized health measures were derived using the Italian version of [10] the Medical Outcomes Study SF-36. The self-administered questionnaire, which patients answered after a brief explanation, assesses the physical and mental components of QoL. Answers were transformed using established scoring algorithms to generate standardized health scale scores ranging from 0 to 100, with better health states resulting in higher scores.

\section{2) Modified fatigue impact test scales}

The MFIS is a modified form of the Fatigue Impact Scale [11]. The questionnaire specifically measure show fatigue impacts the lives of those affected by fatigue-like symptoms. There are 21 items in the scale measuring three domains of fatigue including physical, cognitive, and psychosocial functioning. Participants rate on a 5 -point Likert scale, with $0=$ "Never" to $4=$ "Almost always" their agreement with 21 statements. Total score $(0-84)$ and subscales for physical (0 36), cognitive $(0-40)$ and psychosocial functioning $(0-8)$. A 5 -item version is available and is scored out of 20 . Higher numbers indicate greater fatigue. Administration time is approximately 5 - 10 minutes (5-item version is 2 minutes).

\section{3) The Berg balance scale Italian version}

La BBS-it is a clinical scale assessing balance in seated and in standing position; score runs from 0 (not executable) to 4 (normal performance). The test comprises 14 simple that assess ability in sitting down, standing up, bending down, turning around, standing up on one foot [12]. The scale was validate to be administered to person with MS [13]; BBS-it score of 44 (out of 56) is defined as cut-off score in predict a greater risk of falls in person affected by MS. BBS-it was administrated in many study to assess balance disorder, than to identify person with an higher risk of falls [14]. The scale could also be used to assess treatment effect on person affected by MS [15], [16] especially in comparing efficacy of personalized rehabilitation treatment respect traditional one in balance 
disorder due to vision, somatosensory and vestibular deficit.

\section{4) The Six-Minute Walk Test (6 mWT)}

The Six-min walk measurement we modified the American Thoracic Society (ATS) $6 \mathrm{MW}$ script [17] to maximize effort and better assess motor fatigue. Specifically, we eliminated instructions for permitted rest during testing, emphasized speed and excluded encouragement phrases. Modified 6MW instructions were read prior to each walk. Subjects used his/her typical assistive device and walked back and forth in a 175-foot hallway, pivoting at each end of the hall. Distances walked during each minute and total distance were recorded [18]. We measured heart rate (bpm) and peripheral oxygen saturation (\% SpO2) at the beginning and at the end of the $6 \mathrm{mWT}$ at the base line and twenty months using a pulse oximeter (MD-600P COMDEK, cod. 34290) (Figure 1).

\section{5) Statistical analysis}

Data are presented as mean \pm SD. Student's t-test was performed to compare parametric variables within group. Paired sample t-test was performed to compare parametric variables to paired data of SF36, MFIS, BBS-it and 6mWT the end of treatment (twenty months); $\mathrm{p}$ value $<0.05$ was considered statistically significant. Data were stored by SPSS statistical package, release 13.0 (SPSS Inc., Chicago, IL, USA).

\section{Results}

We included 9 person (average age of $46.22 \pm 8.98$ years), 3 male (average age of $41.33 \pm 8.50$ years) and 6 female (average age of $48.67 \pm 8.65$ years) (Table 1), affected by RRMS. After a twenty months lasting treatment based Riabilitango ${ }^{\circledR}$ method, persons performed all the sessions of treatment protocol; the study had not drop out subjects. We observed significant improvement $(\mathrm{p}<0.05)$ in SF-36 items (Table 2 \& Figure 2), particularly in physical function (PF), vitality (VT), general health (GH), social function (SF); in BBS-it, with a $11.36 \%$ improvement in balance (Figure 3); in MFSI, with a $16.36 \%$ reduction of fatigue (Figure 4); in $6 \mathrm{mWT}$ with a $5.9 \%$ distance $(\mathrm{m}), 2.3 \% \mathrm{Sp} 02,6.44 \%$ beast per minute (bpm) (Figure 5).

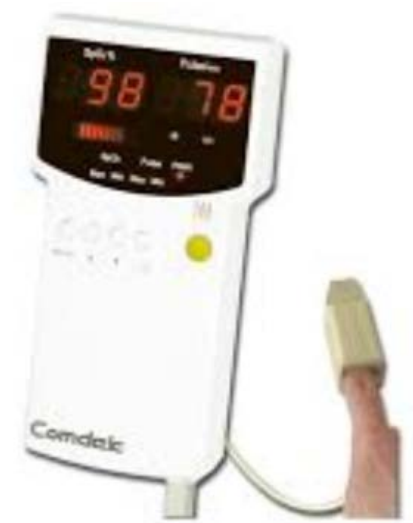

Figure 1. Pulsoximetro portable MD-600P COMDEK (cod. 34290). 
Table 2. Change in health-related quality of life (SF-36).

\begin{tabular}{ccc}
\hline Components & Score Baseline & Twenty months \\
\hline PF (Physical function) & $45.56 \pm 21.42$ & $69.44 \pm 23.64^{*}$ \\
RP (Role limitations/physical) & $38.80 \pm 25.34$ & $66.66 \pm 17.67$ \\
RE (Role limitations/emotional) & $25.40 \pm 27.13$ & $55.00 \pm 45.89$ \\
VT (Vitality) & $45.00 \pm 7.90$ & $67.77 \pm 6.18^{\star}$ \\
MH (Mental health) & $58.22 \pm 16.26$ & $73.33 \pm 3.46$ \\
SF (Social function) & $54.00 \pm 13.86$ & $75.11 \pm 6.25^{\star}$ \\
BP (Bodily pain) & $70.33 \pm 11.00$ & $71.55 \pm 4.87$ \\
GH (General health) & $32.22 \pm 5.06$ & $54.11 \pm 5.20^{\star}$ \\
\hline
\end{tabular}

* Significant change from baseline $(\mathrm{p}<0.05)$.

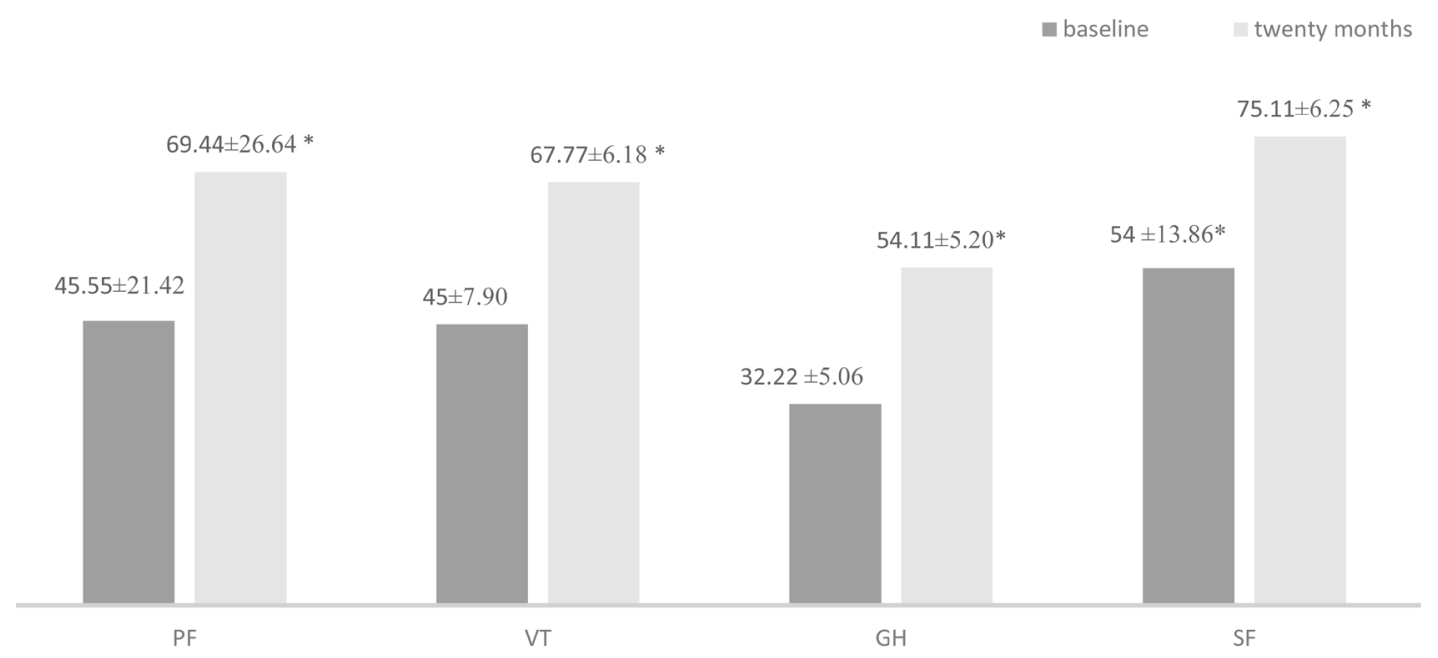

Figure 2. Health-related quality of life (QoL), SF-36. Abbreviation: PF, physical function. VT, vitality. GH, General health. SF, Social function. ${ }^{\star}$ Significant change from baseline $(\mathrm{p}<0.05)$.

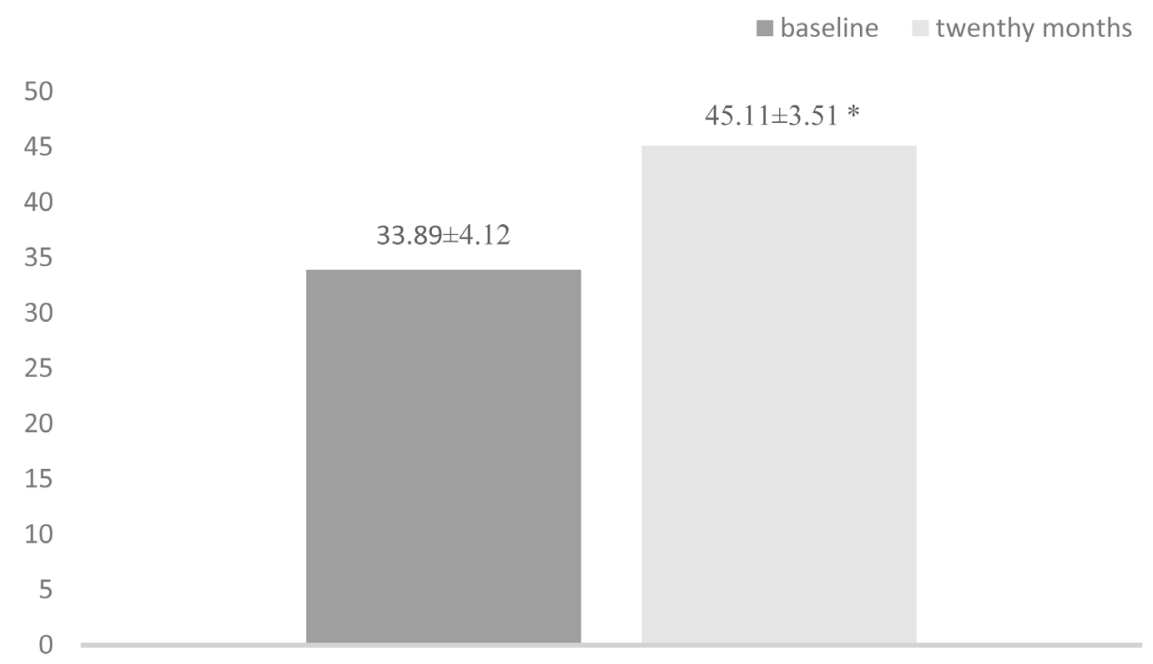

Figure 3. The Berg balance scale, (BBS-it). ${ }^{\star}$ Significant change from baseline $(\mathrm{p}<0.05)$. 
Figure 4. Modified fatigue impact test scales, (MFIS). ${ }^{\star}$ Significant change from baseline $(\mathrm{p}<0.05)$.

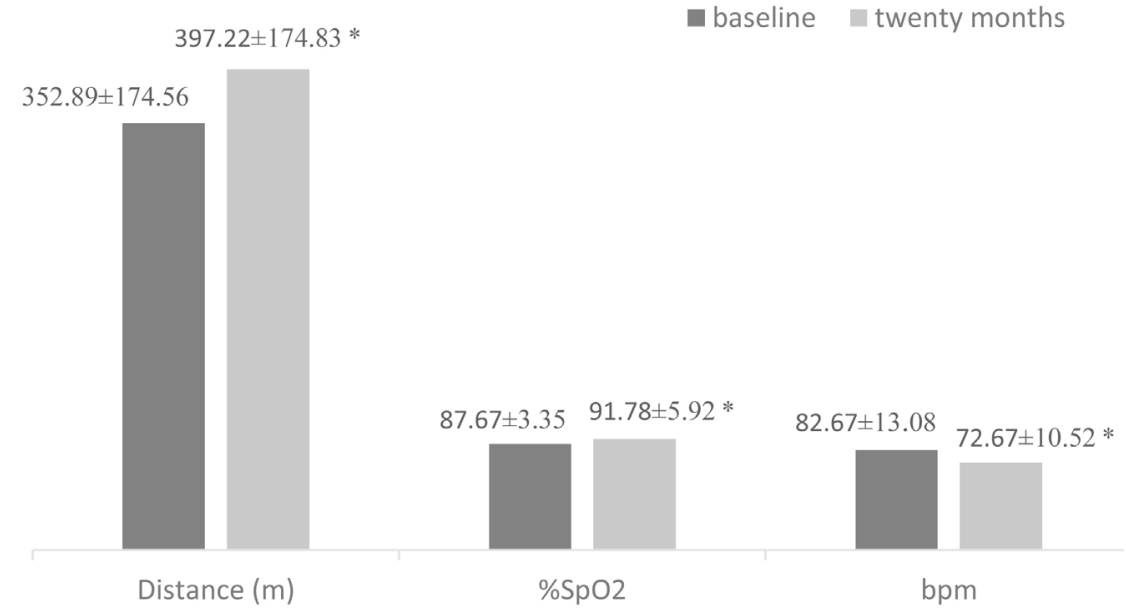

Figure 5. The six minute walk test, $(6 \mathrm{mWT})$. Abbreviation: $\mathrm{m}$, meters. SpO2, saturation of oxygen in arterial blood. bpm, beats for minute. ${ }^{\star}$ Significant change from baseline $(\mathrm{p}<$ $0.05)$.

\section{Discussion}

The study suggests some important elements that should be considered in rehabilitation approach of persons affected by RRMS with EDSS score less than 3 . Riabilitango ${ }^{\circledR}$ method has led to statistically significant $(\mathrm{p}<0.05)$ changes in all the person included, in clinical and psychosocial outcomes. We can suppose that these data could be translate into clinical significance inducing a change in rehabilitation approach to persons affected by MS with an EDSS less than 3, improving functional performances and behavioural aspects.

The group in exam shows a better quality of life in SF-36 scale, in particular in $\mathrm{PF}, \mathrm{VT}, \mathrm{GH}, \mathrm{SF}$ items, benchmarks for activity and participation in daily life and 
work; a decrease in fatigue at MFSI scale, underestimated symptom, hard to objectify in absence of other neurological symptoms, but referred since the early stage of the disease. We found improvement also in balance at BBS-it and in free walk at $6 \mathrm{mWT}$. Dance requires a continuous balance dynamic control, consisting in active contractions of the muscle groups responsible for controlling the body centre of mass (COM) against gravity. Movement based on dance involve balance, coordination and step-step control of movement headed to the target [19]. We can suppose that a more long lasting study could bring out significant differences also in other items of SF-36, as Role limitations/physical (RP), Role limitations/emotional (RE), Mental health (MH), and Bodily pain (BP) (Table 2 \& Figure 2). The beneficial effect of Argentine tango compared to traditional exercise for balance and functional mobility, has been already suggested in studies enrolling elderly participants and persons with PD, but not jet in persons affected by MS [20] [21]. This is the first study designed to evaluate the effect of Riabilitango ${ }^{\circledR}$ not only on motor aspects but also on quality of life in persons with MS.

The participants define Riabilitango ${ }^{\circledR}$ sessions very entertaining and express a positive general satisfaction with environment and with the physiotherapist involved in the study. There were also positive subjective effects in social interaction during the sessions of treatment. Furthermore, engaging in regular positive activities can improve sense of trust and stimulate a better adherence to the treatment. The study has some limits, including a limited number of persons, not compared with a control group and lasting few months. However we have to consider that this is a non-pharmacological study and that this often leads to major difficulties in designing a study. Finally, persons were enrolled into a specific association structure for persons affected by MS, with a high level of awareness about the disease and the traditional treatment; we can suppose that persons enrolled in other settings may have different responses to therapy.

\section{Conclusion}

Dance is largely under-used as socio-rehabilitative intervention for various reasons: limited knowledge of evidence of efficacy, lack of integrated multi-professional paths, and difficulty in considering dance as an exercise. Despite the limitations of this study and the need for further evidence of efficacy to validate Riabilitango ${ }^{\circledR}$ as a rehabilitation treatment of person affected by RRMS with EDSS less than 3 , this method could be considered as a concrete rehabilitation approach and could represent a promising strategy looking at the positive effects it had on the health related quality of life (QoL), fatigue, balance disorder endurance in free walk. Riabilitango ${ }^{\circledR}$, as a rehabilitation alternative approach for person affected by RRMS, could be the ideal path towards a better answer to the request of improvement of skills, wellbeing and health care.

\section{Conflicts of Interest}

The authors declare no conflicts of interest regarding the publication of this paper. 


\section{References}

[1] Kantarci, O. and Wingerchuk, D. (2006) Epidemiology and Natural History of Multiple Sclerosis: New Insights. Current Opinion in Neurology, 19, 248-254. https://doi.org/10.1097/01.wco.0000227033.47458.82

[2] McDonald, W.I. and Ron, M.A. (1999) Multiple Sclerosis: The Disease and Its Manifestations. Philosophical Transactions of the Royal Society B, 354, 1615-1622. https://doi.org/10.1098/rstb.1999.0506

[3] Pugliatti, M., et al. (2006) The Epidemiology of Multiple Sclerosis in Europe. European Journal of Neurology, 13, 700-722. https://doi.org/10.1111/j.1468-1331.2006.01342.x

[4] Kurtzke, J.F. (1983) Rating Neurologic Impairment in Multiple Sclerosis: An Expanded Disability Status Scale (EDSS). Neurology, 33, 1444-1452. https://doi.org/10.1212/WNL.33.11.1444

[5] Benedetti, M.G., et al. (2009) Treadmill Exercise in Early Multiple Sclerosis: A Case Series Study. European Journal of Physical and Rehabilitation Medicine, 45, 53-59.

[6] Pelissier, J., Benaim, C. and Petiot, S. (2001) Locomotor Reeducation and Multiple Sclerosis. A Critical Analysis of the Literature. Revue Neurologique (Paris), 157, 1030-1040.

[7] Krupp, L.B., et al. (1988) Fatigue in Multiple Sclerosis. Arch Neurol, 45, 435-437. https://doi.org/10.1001/archneur.1988.00520280085020

[8] Lötzke, D., Ostermann, T. and Büssing, A. (2015) Argentine Tango in Parkinson Disease: A Systematic Review and Meta-Analysis. BMC Neurology, 15, 226. https://doi.org/10.1186/s12883-015-0484-0

[9] Romenets, S.R., Anangag, J., Fereshtehnejad, S.M., Pelletier, A. and Postuma, R. (2015) Tango for Treatment of Motor and Non-Motor Manifestations in Parkinson's Disease: A Randomized Control Study. Complementary Therapies in Medicine, 23, 175-184. https://doi.org/10.1016/j.ctim.2015.01.015

[10] Apolone, G., Mosconi, P. and Ware Jr., J.E. (1997) Questionario sullo stato di salute SF-36. Manuale d'uso e guida all'interpretazione dei risultati. Guerini e Associati eds.

[11] Fisk, J.D., Ritvo, P.G., Ross, L., Haase, D.A., Marrie, T.J. and Schlech, W.F. (1994) Measuring the Functional Impact of Fatigue: Initial Validation of the Fatigue Impact Scale. Clinical Infectious Diseases, 18, S79-S83. https://doi.org/10.1093/clinids/18.Supplement_1.S79

[12] Coote, S., et al. (2009) Getting the Balance Right: A Randomised Controlled Trial of Physiotherapy and Exercise Interventions for Ambulatory People with Multiple Sclerosis. BMC Neurology, 9, 34. https://doi.org/10.1186/1471-2377-9-34

[13] Cattaneo, D., Jonsdottir, J. and Repetti, S. (2007) Reliability of Four Scales on Balance Disorders in Persons with Multiple Sclerosis. Disability and Rehabilitation, 29, 1920-1925. https://doi.org/10.1080/09638280701191859

[14] Kanekar, N. and Aruin, A.S. (2013) The Role of Clinical and Instrumented Outcome Measures in Balance Control of Individuals with Multiple Sclerosis. Multiple Sclerosis International, 2013, 190162. https://doi.org/10.1155/2013/190162

[15] La Porta, F., Caselli, S., Susassi, S., Cavallini, P., Tennant, A. and Franceschini, M. (2012) Is the Berg Balance Scale an Internally Valid and Reliable Measure of Balance across Different Etiologies in Neurorehabilitation? A Revisited Rasch Analysis Study. Archives of Physical Medicine and Rehabilitation, 93, 1209-1216. https://doi.org/10.1016/j.apmr.2012.02.020 
[16] Brichetto, G., et al. (2014) Tailored Balance Exercises on People with Multiple Sclerosis: A Pilot Randomized, Controlled Study. MultScler.

[17] Society, A.T. (2002) ATS Statement: Guidelines for the Six-Minute Walk Test. American Journal of Respiratory and Critical Care Medicine, 166, 111-117. https://doi.org/10.1164/ajrccm.166.1.at1102

[18] Goldman, M.D., Marrie, R.A. and Cohen, J.A. (2008) Evaluation of the Six-Minute Walk in Multiple Sclerosis Subjects and Healthy Controls. Multiple Sclerosis, 14, 383-390. https://doi.org/10.1177/1352458507082607

[19] Earhart, G.M. (2009) Dance as Therapy for Individuals with Parkinson Disease. European Journal of Physical and Rehabilitation Medicine, 45, 231-238.

[20] Hackney, M.E., Kantorovich, S., Levin, R. and Earhart, G.M. (2007) Effects of Tango on Functional Mobility in Parkinson's Disease: A Preliminary Study. Journal of Neurologic Physical Therapy, 31, 173-179. https://doi.org/10.1097/NPT.0b013e31815ce78b

[21] Duncan, R.P. and Earhart, G.M. (2012) Randomized Controlled Trial of Community Based Dancing to Modify Disease Progression in Parkinson Disease. Neurorehabil Neural Repair, 26, 132-143. https://doi.org/10.1177/1545968311421614 